\title{
A prospective randomized study comparing abdominal sacrocolpopexy and vaginal sacrospinous fixation for the management of vault prolapse
}

\begin{abstract}
Introduction: Pelvic organ prolapse is a common health problem, affecting up to $40 \%$ of parous women over 50 years old, with significant negative influence on quality of life. Some degree of prolapse is common in most parous women, but treatment is required only for the symptomatic patients.
\end{abstract}

Purpose of the study: To compare between efficacy and feasibility of ASC and SSF in patient with POP.

Material and methods: This was a randomized prospective comparative study which included post hysterectomy women attending the Department of Obstetrics and Gynecology in Maternity Kuwait Hospital, Kuwait, who were referred with vault prolapse at least stage II between January 2008 and March 2012. The population study consisted of 74 women. Patients were divided into 2 groups. The first group (Group A) unilateral sacrospinous fixation; the second (Group B) underwent abdominal sacrocolpopexy. Data were normally distributed, which enabled the use of an independent samples t-test to assess the postoperative difference between the two groups and a paired Student's t-test to assess the same group before and after the surgery. The level of significance was 0.05 .

Results: There was no significant statistical difference among the POP-Q measures between the groups pre-operatively. Sixty-nine women (93.2\%) had an optimal anatomical result at first postoperative visit. The three patients with unsatisfied results two in SSF group $(4.5 \%)$ and one in ASC group (3.33\%). Six asymptomatic (stage I prolapse) were diagnosed 12 months after surgery, four patients from SSF group and two from ASC group. None of the six women required additional surgery. There was statistically significant difference between the POP-Q values of $\mathrm{Aa}, \mathrm{Ab}, \mathrm{Pa}, \mathrm{Pb}, \mathrm{C}$ before and after operation $(\mathrm{P}<0.001)$ demonstrating that both techniques were able to improve anatomical parameters. The values of POP-Q, before and after operation $(n=74)$ are seen in Table 3.

Conclusion: Sacrocolpopexy and sacrospinous fixation are both effective in the management of vault prolapse with less procedure and recovery time in sacrospinous fixation group making it more friendly. Further studies are indicated for the comparison between both procedures.

Keywords: pelvic organ prolapse, sacrocolpopexy, sacrospinous fixation, gynecologic surgery, POP Q
Volume 2 Issue I - 2015

\author{
Assem AM Elbiaa,' Magda Kmeikh, ${ }^{2}$ AE \\ Omu, ${ }^{3}$ Mohamed M Farghali' \\ 'AinShams University, Egypt \\ ${ }^{2}$ Kuwait University, Kuwait \\ ${ }^{3}$ Department of Obstetrics and Gynecology, Kuwait University, \\ Kuwait
}

Correspondence: Assem El-Biaa, Ain Shams University, Khalifa El-Maamon St, Abbasiya Sq., Cairo II 566, Egypt, Tel 0096597337I43,Email assemelbiaa@gmail.com

Received: September 15, 2014 | Published: February 14, 2015
Abbreviations: SSF, sacrospinous ligament fixation; POP-Q, pelvic organ prolapse quantification

\section{Introduction}

Pelvic organ prolapse is a common health problem, affecting up to $40 \%$ of parous women over 50 years old, with significant negative influence on quality of life. ${ }^{1}$ Some degree of prolapse is common in most parous women, but treatment is required only for the symptomatic patients. ${ }^{2}$

Surgery for prolapse is one of the most common operations Performed in gynecology. In women, the lifetime risk of needing surgery for prolapse by the age of 80 is around $11 \%$. It is interesting to note that $25 \%$ of these operations are performed for recurrent prolapse, suggesting that success rates for initial operations are poor. ${ }^{3}$ The ideal procedure for vaginal apical support has yet to be determined. The past decade has seen several innovations in the treatment of prolapse due to greater understanding of pelvic anatomy and pathophysiology. ${ }^{2}$
Abdominal sacral colpopexy is the gold standard abdominal procedure used for apical prolapse. Success rates range from $78 \%$ to $100 \%$. This is probably the only procedure in prolapse surgery where there is levell evidence to use synthetic mesh. Major complications from this procedure are rare but serious. ${ }^{4}$

Sacrospinous ligament fixation (SSF) is a vaginal procedure that is well established for POP repair. However, data are limited on the comparative efficacy of abdominal sacrocolpopexy and SSF. ${ }^{5}$

We conducted a randomized, non-inferiority trial to determine whether the efficacy of sacrospinous fixation is similar to abdominal sacrocolpopexy in women with symptomatic vault prolapse (POP-Q) stage 2 or higher.

\section{Materials and methods}

This was a randomized prospective comparative study which included post-hysterectomy women attending the Department of Obstetrics and Gynecology in Maternity Kuwait Hospital, Kuwait, 
who were referred with vault prolapse at least stage II between January 2008 and March 2012. Subjects were excluded if they had vaginal or pelvic infections, any chronic disabling diseases, above 70 years old. The population study consisted of 74 women. Characteristics of the patients were shown in Table 1. Approval of ethical committee was conducted before collecting any of these data.

Table I Characteristics of the patients in 2 surgical groups

\begin{tabular}{lll}
\hline & Vaginal SSF & Abdominal SCP \\
\hline Number of patients & 37 & 37 \\
Age (years) & $57.8( \pm \mid 2.3)$ & $60 . I( \pm \mid 0.5)$ \\
Parity & $4.5( \pm 2.5)$ & $4.3( \pm 2.6)$ \\
Body mass index $(\mathrm{kg} / \mathrm{m} 2)$ & $29.6( \pm 4.2)$ & $28.2( \pm 5 . \mathrm{I})$ \\
History of prolapse surgery* & $8(2 I .62 \%)$ & $8(21.62 \%)$ \\
$\begin{array}{l}\text { Anterior colporraphy } \\
\text { Anterior and posterior }\end{array}$ & 4 & 3 \\
$\begin{array}{l}\text { colporraphy } \\
\text { Vaginal Sacrospinous fixation }\end{array}$ & 0 & 2
\end{tabular}

\section{Cause of Hysterectomy}

Fibroid uterus

Adenomyosis

DUB

Endometrial carcinoma

Uterine prolapse at least stage II

Ovarian Pathology

Comorbidity**

Hypertension

Diabetes mellitus

Hypercholesterolaemia

Hypothyroidism

Chronic obstructive pulmonary

disease

Cardiovascular accidents

Prolapse stage pre-operative

$\begin{array}{lll}\text { Stage } 0 & 0 & 0 \\ \text { Stage I } & 0 & 0 \\ \text { Stage II } & 9(24.3 \%) & 9(24.3 \%) \\ \text { Stage III } & 13(35.1 \%) & 9(24.3 \%) \\ \text { Stage IV } & 15(40.5 \%) & 12(32.4 \%) \\ \text { Performed surgical procedures } & \\ \text { Vaginal hysterectomy } & 37(100 \%) & - \\ \text { Sacro-colpopexy } & - & 37(100 \%) \\ \text { Anterior colporraphy } & 34(83) & 10(27 \%) \\ \text { Posterior colporraphy } & 35(85) & 10(27 \%) \\ \text { Colposuspension } & - & 22(59.5) \\ \text { Kelly’s suture } & 25(67.6 \%) & -\end{array}$

All patients underwent a standardized Urogynecologic interview that included pelvic organ prolapse quantification (POP-Q) by the authors and a classification of the genital prolapse according to the recommendations of the ICS.

Preoperatively, the 2 groups were homogeneous with respect to age, body mass index, stage of apical prolapse. All eligible women who agreed to participate in the study and who provided written informed consent were enrolled (74 patients). The patients were allocated randomly to one of the two surgery groups. The first group (Group A) unilateral sacrospinous fixation; the second (Group B) underwent abdominal. All patients were consented for random selection for surgery.

All SSF were performed unilaterally to the right sacrospinous ligament. The posterior vaginal wall was incised and separated from the rectum and access to sacrospinous ligament was obtained through the pararectal space. The right ischial spine was localised digitally and the ligament was made visible through blunt dissection. One permanent suture (Prolene 1.0, Ethicon, Somerville, NJ, USA) and one delayed absorbable (Vicryl 1.0, Ethicon, Somerville, NJ, USA) were placed through the right sacrospinous ligament at least $2 \mathrm{~cm}$ from the ischial spine. The sutures were placed through the vaginal apex. Two thirds of the posterior vaginal wall was closed with absorbable sutures (Vicryl 2, Ethicon, Somerville, NJ, USA). The suture was then tied, drawing the apex of the vaginal vault towards the sacrospinous ligament. The rest of posterior vaginal wall incision was then closed.

In abdominal sacrocolpopexy, the abdomen was entered via a transverse incision. The bladder and rectum wall dissected as needed. A transverse incision was made in the peritoneum overlying the vault to expose the pubocervical and rectovaginal fasciae. A longitudinal incision was made over the anterior surface of sacrum one to expose the anterior longitudinal ligament. The posterior wall peritoneum was reflected and bisected, starting from the anterior surface of the sacrum to the transverse incision over the vault, taking care to avoid injury to the presacral vessels, the right common iliac vessels, ureters, and the sigmoid colon. Mersiline tape was attached to the vaginal vault and to the anterior longitudinal ligament overlying the sacrum, without being too tight, to help maintain a horizontal rather than an upright direction of the upper vagina on standing. The bisected posterior peritoneum was sutured with vicryl $2 / 0$.

All surgeries were performed by experienced gynecologists who were familiar with both techniques. The patients were seen 4-6 weeks after surgery, and then at 6,12 and 24 months. There were no drop-outs in the follow-up. The preoperative assessments and the postoperative follow-ups were conducted by the authors at alternating visits.

All numerical data were expressed as the means \pm standard deviations. To detect preoperative intergroup differences, we used a Mann-Whitney U test for continuous variables and a chi-square test for categorical variables. Data were normally distributed, which enabled the use of an independent samples t-test to assess the postoperative difference between the two groups and a paired Student's t-test to assess the same group before and after the surgery. The level of significance was 0.05 .

\section{Results}

Operations were performed under general anesthesia in $12.1 \%(9)$ or epidural anesthesia $87.8 \%(65)$ of cases. The mean operating time was $44 \pm 16 \mathrm{~min}$ for sacrospinous group and $65 \pm 18 \mathrm{~min}$ for abdominal sacrocolpopexy group. The presence of an associated cystocele was 
noted in $34(83 \%)$ cases which were corrected by anterior repair, and $35(85 \%)$ cases had rectocele corrected by posterior repair and in VSSF group. While $10(27 \%)$ patients had anterior repair and 10 $(27 \%)$ had posterior repair in the ASC group. $25(67.6 \%)$ patients of SSF group had Kelly`s suture due to stress urinary incontinence and $22(59.5 \%)$ patients had Burchcolpo suspension in ASC group.

In sacrospinous group, the overall perioperative complication rate was $35.1 \%$. Two patients $(5.4 \%)$ had intraoperative complications One patient had injury to the inferior gluteal vein on passing the suture needle through the sacrospinous ligament. Blood loss was about 200 $\mathrm{ml}$, and bleeding was controlled by compression and vaginal pack was left for 24 hours. Bladder injury occured in one patient during anterior repair. The injury was noted during surgery and sutured immediately, with simple stitches with foley's catheter left for 7 days postoperative. Early complications occured in 6 cases $(13.6 \%)$. Hematoma of the para-rectal fossa occured in 2 cases. This hematoma resolved spontaneously within a few days without surgical intervention. Acute urinary retention occured in 2 cases. In one patient retention resolved after 3 days of bladder drainage with a Foley catheter, the other patient was treated medically with alpha-blockers. For this patient, the mean duration of hospitalization was 14 days. Paralyticileus occurred in one woman and resolved on day 5. Gluteal pain or right groin pain occurred in another woman and was treated with non-steroidal antiinflammatory drugs. Late complications occured in 5 cases $(11.3 \%)$, with high vaginal swabs revealing candidiasis, they were successfully treated with antifungals. The mean length of hospital stay was $1 \pm 2$ days for SSF groups and $2 \pm 2$ for ASC group.
In ASC group there were 12 complications, 3 patients had bleeding during surgery due to dissection and injury to venous presacralplexus and compression of the plexus was enough in 2 of the patients while $3^{\text {rd }}$ one received blood transfusion. Estimated loss $200 \mathrm{ml}$ while in the $3^{\text {rd }}$ one it was $500 \mathrm{ml}$. four patients had wound infection and received antibiotic according to culture and sensitivity result.

Five patients had paralytic ileus and recovered spontaneously on the $3^{\text {rd }}$ day postoperative (Table 2). In SSF group 34 (83\%) patients had an anterior repair and $35(85 \%)$ patients had a posterior repair. while in the ASC group 10(27\%) patients had an anterior repair and $10(27 \%)$ patients had a posterior repair. In ACC group 22 patients had colposuspension for stress urinary incontinence while in SSF group 25 patients had Kelly's suture.

There was no significant statistical difference among the POP-Q measures between the groups pre-operatively. Sixty-nine women $(93.2 \%)$ had an optimal anatomical result at first postoperative visit. The three patients with unsatisfied results two in SSF group (4.5\%) and one in ASC group (3.33\%). Six asymptomatic (stage I prolapse) were diagnosed 12 months after surgery, four patients from SSF group and two from ASC group. None of the six women required additional surgery. There was statistically significant difference between the $\mathrm{POP}-\mathrm{Q}$ values of $\mathrm{Aa}, \mathrm{Ab}, \mathrm{Pa}, \mathrm{Pb}, \mathrm{C}$ before and after operation $(\mathrm{P}<0.001)$ demonstrating that both techniques were able to improve anatomical parameters. The values of POP-Q, before and after operation $(n=74)$ are seen in Table 3.

Table 2 Shows complications in both groups

\begin{tabular}{|c|c|c|c|c|c|c|c|}
\hline & \multicolumn{2}{|l|}{ Group ASC } & \multicolumn{2}{|l|}{ Group SSF } & \multirow{2}{*}{3 month } & \multirow{2}{*}{ I year } & \multirow{2}{*}{2 years } \\
\hline & Range & Mean & Range & Mean & & & \\
\hline Age & $55-60$ & 53 & $54-60$ & 52 & & & \\
\hline BMI & $20-24$ & 22 & $21-24$ & 21 & & & \\
\hline Parity & P6-II & P7 & P5-P9 & P6 & & & \\
\hline Time of procedure & & $44 \min \pm 16$ & & $65 \pm 18 \min$ & & & \\
\hline Blood transfusion & 1 & & No & & & & \\
\hline Postoperative recovery & 2 days & & I day & & & & \\
\hline Complications & $12(32.4 \%)$ & & $13(35.1 \%)$ & & $-V E$ & $-V E$ & $-V E$ \\
\hline Bleeding & 3 & & 1 & & - & - & - \\
\hline Infection & 4 wound infections & & 5 vaginitis & & $-V E$ & $-V E$ & $-V E$ \\
\hline Urine retention & & & 2 & & & & \\
\hline Injury to bladder & NO & & I & & - & - & - \\
\hline Injury to rectum & NO & & NO & & - & - & - \\
\hline Gluteal pain & NO & & 1 & & $-V E$ & $-V E$ & $-V E$ \\
\hline Hematoma of pararectal fossa & NO & & 2 & & $-V E$ & $-V E$ & $-V E$ \\
\hline Paralytic ileus & 5 & & I & & $-V E$ & $-V E$ & $-V E$ \\
\hline
\end{tabular}


Table 3 POP-Q in sacrospinous (Group A) and abdominal sacro-colpopexy (Group B) groups' pre-operative and 4 weeks' post-operative

\begin{tabular}{|c|c|c|c|}
\hline & Group SSF & Group ASC & pa \\
\hline \multicolumn{4}{|l|}{$\mathrm{Aa}$} \\
\hline Pre-operative & $1.23(1.52)$ & 1.97 (1.18) & 0.679 \\
\hline Post-operative & $-0.95(0.61)$ & $-0.87(0.4 I)$ & 0.974 \\
\hline $\mathrm{pb}$ & $<0.01$ & $<0.01$ & \\
\hline \multicolumn{4}{|l|}{$\mathbf{B a}$} \\
\hline Pre-operative & $3.24(1.67)$ & $2.93(1.81)$ & 0.901 \\
\hline Post-operative & $-0.56(0.31)$ & $-0.88(0.79)$ & 0.891 \\
\hline $\mathrm{pb}$ & $<0.01$ & $<0.01$ & \\
\hline \multicolumn{4}{|l|}{ C } \\
\hline Pre-operative & $-0.07(4.22)$ & $-0.96(4.10)$ & 0.938 \\
\hline Post-operative & $-0.4 \mid(2.50)$ & $-0.16(2.67)$ & 0.954 \\
\hline $\mathrm{pb}$ & $<0.01$ & $<0.01$ & \\
\hline \multicolumn{4}{|l|}{ Bp } \\
\hline Pre-operative & $0.64(2.96)$ & $0.51(3.17)$ & 0.904 \\
\hline Post-operative & $-0.27(1.15)$ & $-0.88(1.58)$ & 0.84 \\
\hline $\mathrm{pb}$ & $<0.01$ & $<0.01$ & \\
\hline \multicolumn{4}{|l|}{ Ap } \\
\hline Pre-operative & $+2.3(1.35)$ & $+2.1(1.6 \mathrm{I})$ & 0.982 \\
\hline Post-operative & $-2.1(2.25)$ & $-2.4(1.99)$ & 0.985 \\
\hline $\mathrm{pb}$ & $<0.01$ & $<0.01$ & \\
\hline \multicolumn{4}{|l|}{ GH } \\
\hline Pre-operative & $4.79(0.67)$ & $4.81(0.92)$ & 0.995 \\
\hline Post-operative & $2.76(0.55)$ & $2.46(0.48)$ & 0.896 \\
\hline $\mathrm{pb}$ & 0.46 & 0.383 & \\
\hline \multicolumn{4}{|l|}{ PB } \\
\hline Pre-operative & $2.39(0.83)$ & $2.81(0.67)$ & 0.85 \\
\hline Post-operative & $-2.5(0.82)$ & $-2.6(1.13)$ & 0.972 \\
\hline $\mathrm{pb}$ & 0.472 & 0.614 & \\
\hline \multicolumn{4}{|l|}{ TVL } \\
\hline Pre-operative & 7.45 (0.99) & 7.17 (1.32) & 0.942 \\
\hline Post-operative & $9.89(0.75)$ & $10.17(0.47)$ & 0.947 \\
\hline $\mathrm{pb}$ & 0.722 & 0.621 & \\
\hline
\end{tabular}

\section{Discussion}

Genital prolapse is a common condition whose incidence is increasing representing a major public health issue. Hysterectomy for pelvic organ prolapse appears to be a particular risk factor. The risk of prolapse repair after hysterectomy was 4.7 times higher in women whose initial hysterectomy was indicated for pelvic organ prolapse and 8 times higher if preoperative prolapse grade 2 or more was present. $^{6}$
The lack of standardized definitions for surgical success following pelvic organ prolapse (POP) surgery has resulted in highly variable estimates of success. Studies with the lowest success rates defined success using more stringent anatomic support while those with the highest success rates generally used subjective outcomes such as satisfaction and resolution of POP symptoms. Barber et al. ${ }^{7}$ stated that More than a hundred surgical techniques have been proposed, but the choice is not unique because no therapeutic has demonstrated its superiority.

In Barber et al. ${ }^{7}$ study, success after POP surgery included subjective criteria as the absence of bulge symptoms in addition to anatomic criteria (using the hymen as a threshold for anatomic success) and no need for re-surgery.

In several retrospective and prospective studies it has been shown that sacrospinous fixation in case of uterine or vaginal vault prolapse is a safe and effective treatment. ${ }^{8,9}$ In our study, Seventy-one women $(95.94 \%)$ had an optimal anatomical result at first postoperative visit. The success rate of SSF group and ASC group are (95.5\%) and $(96.66 \%)$ respectively. Six asymptomatic (stage I prolapse) were diagnosed 12 months after surgery, none of the six women required additional surgery. There was a significant statistical difference between the POP-Q of Aa, Ba, Ap, Bp, and D before and after the operation $(\mathrm{P}<0.001)$.

In published literature reviews, the average mean follow-up after SSLP is 13.8 months to 4.8 years. Benson et al. ${ }^{10}$ and Maher ${ }^{11}$ followed up cases for 1 year unlike our study where follow up was 24 months. The success rate of SSLF was $84.7 \%$-97\%. Recurrences usually happened within six months post operation. ${ }^{12,13}$

Sacrocolpopexy is an effective option for the correction of advanced POP. The major advantages of sacrocolpopexy are excellent ten-year success rates, and for the sexually active patient provide the longest possible vaginal length. In our study total vaginal length postoperative in ASC 10.17 compared to in 9.89 in SSF group however this not statically significant (p 0.947).

Many studies have shown that sacrospinous fixation is effective for vaginal vault repair. ${ }^{14}$ The advantages of the vaginal were supported by Maher et al. ${ }^{10}$ in a meta-analysis: the shorter operative time, less complications, faster recovery and costless.

In the study of Abeera Choudhry et al. ${ }^{15}$ they conclude that SSF is a patient friendly operation (shorter procedure and quicker recovery) with little short-term morbidity and excellent functional results, which are equivalent to sacrocolpopexy. To settle the war between abdominal VS vaginal route we need to design bigger and longer-term high quality clinical trials.

In the study of Aigmueller et al. ${ }^{16} 99$ women (mean 66 years) underwent vaginal SSF for vault prolapse. He contacted all patients 2-15 years after surgery for examination (POP-Q, survey). Sixteen out of $55(29 \%)$ patients, who completed follow-up, presented with cystocele, three patients with rectocele, and four patients had a recurrent vault prolapse. As for quality of life, 42/55 (76\%) patients reported lower urinary tract symptoms, but only $9 / 55$ (16\%) felt a sensation of prolapse. Ten out of 24 patients, who were still sexually active, reported symptoms of sexual dysfunction. There was no correlation between lengths of follow-up and anatomical or functional results. Vaginal sacrospinous fixation resulted in excellent vault suspension but $29 \%$ of the patients developed cystocele formation. Only $16 \%$ of patients reported symptoms of descent. 
There are only two randomized controlled trials that compare the vaginal and abdominal routes for vault prolapse surgery. Surprisingly these trials report on only 175 cases. One trial was done in by Benson et al and the other in by Maher et al. ${ }^{15}$

\section{Conclusion}

Sacrocolpopexy and sacrospinous fixation are both effective in the management of vault prolapse with less procedure and recovery time in sacrospinous fixation group making it more friendly. Further studies are indicated for the comparison between both procedures.

\section{Authors contributions}

Assem AM Elbiaa: did the procedure, collected and analyzed the data and wrote the manuscript

M Al-Azemi: did the procedure, collected data and critically reviewed the manuscript.

Mohamed M Farghali: did the procedure, critically reviewed the manuscript.

AE Omu: did the procedure collected data and critically reviewed the manuscript.

\section{Acknowledgments}

None.

\section{Conflict of interest}

The authors declare that there is no conflict of interest.

\section{References}

1. Slieker-ten Hove MC, Pool-Goudzwaard AL, Eijkemans MJ, et al The prevalence of pelvic organ prolapse symptoms and signs and their relation with bladder and bowel disorders in a general female population. Int Urogynecol J Pelvic Floor Dysfunct. 2009;20(9):1037-1045.

2. Elias Kovoor, Paul Hooper. Assessment and management of pelvic organ prolapse. Obstetrics, Gynecology and Reproductive medicine. 2008;18(9):241-246

3. Olsen AL, Smith VJ, Bergstrom JO, et al. Epidemiology of surgically managed pelvic organ prolapse and urinary incontinence. Obstet Gynecol. 1997;89(4):501-506
4. Connell KA. Elastogenesis in the vaginal wall and pelvic organ prolapse. N Engl J Med. 2011;364(24):2356-2358.

5. Gilleran JP, Johnson M, Hundley A. Robotic-assisted laparoscopic mesh sacrocolpopexy. Ther Adv Urol. 2010;2(5-06):195-208.

6. Dallenbach P, Kaelin-Gambirasio I, Dubuisson JB, et al. Risk factors for pelvic organ prolapse repair after hysterectomy. Obstet Gynecol. 2007;110(3):625-632.

7. Barber MD, Brubaker L, Nygaard I, et al. Defining success after surgery for pelvic organ prolapse. Obstet gynecol. 2009;114(3):600-609.

8. Morgan DM, Rogers MA, Huebner M, et al. Heterogeneity in anatomic outcome of sacrospinous ligament fixation for prolapse: a systematic review. Obstet Gynecol. 2007;109(6):1424-1433.

9. Dietz V, Huisman M, de Jong J, et al. Functional outcome after sacrospinous hysteropexy for uterine descensus. Int Urogynecol J Pelvic Floor Dysfunct. 2008;19(6):747-752.

10. Benson JT, Leucente V, McClellan E. Vaginal versus abdominal reconstructive surgery for the treatment of pelvic support defects:a prospective randomized study with long term evaluation. Am J Obstet Gynecol. 1996;175(6):1418-1421.

11. Maher CF, Qatawneh AM, Dwyer PL, et al. Abdominal sacrocolpopexy or vaginal sacrospinous colpopexy for vaginal vault prolapse: a prospective randomized study. Am J Obstet Gynecol. 2004;190(1):20-26.

12. Lantzsch T, Goepel C, Wolters M, et al. Sacrospinous ligament fixation for vaginal vault prolapse. Arch Gynecol Obstet. 2001;265(1):21-25.

13. David-Montefiore E, Barranger E, Dubernard G, et al. Functional results and quality-of-life after bilateral sacrospinous ligament fixation for genital prolapse. Eur J Obstet Gynecol Reprod Biol. 2007;132(2):209213.

14. Detollenaere RJ, den Boon J, Stekelenburg J, et al. Treatment of uterine prolapse stage 2 or higher: a randomized multicenter trial comparing sacrospinous fixation with vaginal hysterectomy (SAVE U trial). BMC Womens Health. 2011;11:4.

15. Abeera Choudhry, Irfan Shukr, Humaira Choudhry, et al. Abdominal sacrocolpopexy vs vaginal sacrospinous ligament fixation for vaginal vault prolapse. Pakistan Armed Forces Medical Journal. 2009;(5).

16. Aigmueller T, Riss P, Dungl A, et al. Long-term follow-up after vaginal sacrospinous fixation: patient satisfaction, anatomical results and quality of life. Int Urogynecol J Pelvic Floor Dysfunct.2008;19(7):965-969. 